\title{
Anti-VEGF therapy in mRCC: differences between Asian and non-Asian patients
}

\author{
Y Wang ${ }^{1}$, T K Choueiri ${ }^{2}, \mathrm{~J}-\mathrm{L} \mathrm{Lee}^{3}, \mathrm{M}-\mathrm{H} \mathrm{Tan}^{4}$, S Y Rha ${ }^{5}$, S A North ${ }^{6}$, C K Kollmannsberger ${ }^{7}$, D F McDermott ${ }^{8}$ \\ and D Y C Heng ${ }^{\star, 9}$ \\ ${ }^{1}$ University of Calgary, Calgary, Alberta, Canada; ${ }^{2}$ Kidney Cancer Center, Dana-Farber Cancer Institute/Brigham and Women's \\ Hospital, Harvard Medical School, Boston, Massachusetts, USA; ${ }^{3}$ Department of Oncology, Asan Medical Center, University of \\ Ulsan College of Medicine, Seoul, South Korea; ${ }^{4}$ National Cancer Centre, Singapore, Singapore; ${ }^{5}$ Yonsei Cancer Center, Yonsei \\ University College of Medicine, Seoul, South Korea; ${ }^{6}$ Cross Cancer Institute, Edmonton, Alberta, Canada; ${ }^{7}$ British Columbia \\ Cancer Agency, Vancouver, British Columbia, Canada; ${ }^{8}$ Division of Hematology/Oncology, Department of Medicine, Beth Israel \\ Deaconess Medical Center, Massachusetts, USA and ${ }^{9}$ Tom Baker Cancer Centre, University of Calgary, Calgary, Alberta, Canada
}

Background: Several reports suggest that vascular endothelial growth factor (VEGF)-targeted therapy in metastatic renal cell carcinoma (mRCC) may be more toxic in Asian vs non-Asian populations. Comparative efficacy of these agents with respect to ethnicity is not well characterised.

Methods: A multicentre, retrospective, cohort study using Asian and non-Asian centres which collected data on ethnicity, dose reductions and outcomes using the International mRCC Database Consortium.

Results: This study included 1024 (464 Asian, 560 non-Asian) patients with a 29.4 months median follow-up. The percentage of dose modifications/reductions between non-Asians and Asians was similar ( $55 \%$ vs $61 \% P=0.1197)$. When adjusted for risk groups, there was no difference in overall or progression-free survival between non-Asians and Asians. Patients with dose reductions due to toxicity had longer treatment durations and overall survival than those who did not in both non-Asian (10.6 vs 5.0 months, $P<0.0001 ; 22.6$ vs 16.1 months, $P=0.0016$, respectively) and Asian populations ( 8.9 vs 5.4 months, $P=0.0028 ; 28.0$ vs 18.7 months, $P=0.0069$, respectively).

Conclusions: Adjusting for risk groups, there appears to be no difference in outcome between Asian vs non-Asian patients with mRCC treated with VEGF-targeted therapy. Judicious dose reductions may allow for better outcomes in both populations due to longer treatment durations, but direct comparisons are needed.

The treatment of metastatic renal cell carcinoma (mRCC) has been revolutionised by the introduction of a novel class of therapies targeting vascular endothelial growth factor (VEGF). These drugs include sunitinib, sorafenib, bevacizumab, pazopanib, and axitinib, which have all improved response rates and progression-free survival (PFS) compared with previous standards of care.

Despite their efficacy, these drugs have toxicities. For example, the number of patients requiring treatment interruptions, and dose reductions due to sunitinib toxicities reached $38 \%$ and $32 \%$, respectively, in the original phase III registration study
(Motzer et al, 2007). Common and/or serious toxicities associated with sunitinib include fatigue, hand-foot syndrome, diarrhea, hypertension, mucositis/stomatitis, hypothyroidism, and cardiotoxicity (Kollmannsberger et al, 2007; Motzer et al, 2007; Telli et al, 2008). Similarly, dose interruptions and dose reductions, were required in $21 \%$ and $13 \%$ of patients on sorafenib, respectively, and $10 \%$ required drug discontinuation because of adverse events (Escudier et al, 2007). Common toxicities include diarrhea, skin reaction or rash, fatigue, and hand-foot syndrome (Escudier et al, 2007). 
Since their widespread use around the world, several reports have indicated that VEGF-targeted therapy in mRCC may be more toxic in Asian versus Caucasian populations (Tomita et al, 2010; Zhou, 2012). In a phase II study of sunitinib in Japanese patients with $\mathrm{mRCC}, 78 \%$ of patients required dose reduction and $25 \%$ of patients required treatment discontinuation due to treatmentrelated adverse events (Tomita et al, 2010). However, comparative efficacy of these agents with respect to ethnicity is not well characterised.

Using a large database of patients with mRCC treated with contemporary targeted therapy, the International mRCC Database Consortium (IMDC), we sought to determine whether these differences in toxicities resulted in a difference in the rate of dose reductions and discontinuation of therapy in patients from Asian centres when compared with patients from non-Asian centres and whether PFS and overall survival (OS) is adversely affected as a result. Secondary analysis included the comparison of patients who have had dose reductions versus full dose treatment and their overall treatment duration on the effect of PFS and OS.

\section{METHODS}

Study population. Eight centres participating in the IMDC with available dose reduction and race data on patients with mRCC treated with VEGF-targeted therapy were included in this analysis. Patients were identified from consecutive population-based patient samples from 2005 to 2011 at these centres. Non-Asian patients were derived from cancer centres in Canada (Alberta Health Services Cancer Control, British Columbia Cancer Agency) and the United States (Dana-Farber Cancer Institute, Beth Israel Deaconess Medical Center). Asian patients were derived from centres in Korea (Asan Medical Center, Yonsei Cancer Center) and Singapore (National Cancer Center). Asian patients from nonAsian centres were excluded $(n=8)$ and non-Asian patients from Asian centres were excluded $(n=3)$.

Patients may have been treated on clinical trial protocols or off protocol and may have been treated at major academic centres, or community oncology centres. Baseline patient characteristics and outcome data were collected using uniform data collection templates in this retrospective analysis. Regulatory approval from local institutional review boards or research ethics boards was obtained for each centre.

Endpoints. The primary endpoint was OS, which was defined as the time from drug initiation to the date of death from any cause or was censored at the last follow-up. Progression-free survival was defined as the time from drug initiation to the time of disease progression, or death, or was censored at the last follow-up. We defined disease progression according to standard Response Evaluation Criteria in Solid Tumors (RECIST 1.0) (Eisenhauer et al, 2009).

Statistics (data analysis). Kaplan-Meier curves were constructed to compare PFS and OS in patients in Asian populations versus non-Asian populations. Progression-free survival and OS were also determined for patients in Asian and non-Asian centres based on whether or not they required dose reductions. It is assumed that dose reductions are due to clinically significant toxicities and thus are most important to capture. A dose reduction is defined as any change in dose to $<50 \mathrm{mg}$ once daily for 4 weeks out of a 6 -week treatment cycle for sunitinib, $<400 \mathrm{mg}$ twice daily for sorafenib, $<10 \mathrm{mg} \mathrm{kg}^{-\mathrm{g}}$ every 2 weeks for bevacizumab, and $<800 \mathrm{mg}$ once daily for pazopanib, and $<5 \mathrm{mg}$ twice daily for axitinib.

Chi-squared tests were used to compare percentage values and continuous variables were compared using the two-sided $t$-test. All statistical tests were two-sided, and $P$-values of $<0.05$ were considered significant. Proportional hazards regression was carried out to adjust the PFS and OS hazard ratio estimates by IMDC prognostic criteria which stratify patients into favourable, intermediate, and poor risk groups (Heng et al, 2009). All analyses were carried out on SAS 9.2 (SAS Institute Inc., Cary, NC, USA).

\section{RESULTS}

Baseline characteristics. In total, 1024 patients treated with antiVEGF therapy with a median follow-up of 29.4 months were included in this analysis (Table 1). Of those, 464 patients (45\%) were derived from the Asian centres and 560 (55\%) from non-Asian centres. As per IMDC prognostic factors (Heng et al, 2009), the Asian versus non-Asian patients in favourable, intermediate, and poor risk categories were $13 \%$ vs $22 \%, 69 \%$ vs $50 \%$, and $17 \%$ vs $24 \%$, respectively (Table 1). Among the Asian patients, $84 \%$ received sunitinib, $15 \%$ sorafenib, and $1 \%$ pazopanib. Among the non-Asian patients, $73 \%$ received sunitinib, $20 \%$ sorafenib, and $7 \%$ bevacizumab-based treatment. A description of baseline characteristics of patients from the Asian vs non-Asian population is found in Table 1.

Dose modifications and outcomes. The percentage of dose modifications/reductions between non-Asians and Asians was similar (55\% vs 61\%, $P=0.1197$ ) but more patients completely discontinued treatment due to toxicity in the non-Asian versus the Asian group (28\% vs 21\%, $P=0.0197)$ (Table 2). There was no statistical difference in PFS in Asian vs non-Asian patients (7.2 vs 6.9 months, $P=0.0804$ ) (Figure 1$)$. When adjusted for the IDMC poor prognostic criteria (Heng et al, 2009), there was no difference in OS (HR 0.887, 95\% CI $0.729-1.08, P=0.2322$ ) or PFS (HR $1.069,95 \%$ CI $0.910-1.256, P=0.4184)$ between non-Asians and Asians (Table 3).

Interestingly, when patients were dose reduced due to toxicity, they had a longer treatment duration and OS than those who did not have toxicity requiring a dose reduction in both the non-Asian (10.6 vs 5.0 months, $P<0.0001$, and 22.6 vs 16.1 months, $P=0.0016$, respectively) and in the Asian populations (8.9 vs 5.4 months, $P=0.0028$, and 28.0 vs 18.7 months, $P=0.0069$ ) (Figures 2 and 3, Table 4).

Table 1. Comparison of non-Asian population and Asian population characteristics

\begin{tabular}{|l|c|c|c|}
\hline & $\begin{array}{c}\text { Non-Asian } \\
\text { population, } \\
\mathbf{n}=\mathbf{5 6 0}\end{array}$ & $\begin{array}{c}\text { Asian } \\
\text { population, } \\
\mathbf{n}=\mathbf{4 6 4}\end{array}$ & P-value \\
\hline Characteristic & & & \\
\hline Heng et al risk group & 22 & 13 & \\
$\quad$ Favourable (\%) & 50 & 69 & $<0.0001$ \\
Intermediate (\%) & 24 & 17 & \\
Poor (\%) & 27 & 17 & $<0.0001$ \\
KPS <80\% & 61 & 58 & $<0.0001$ \\
Median age (years) & 72 & 72 & 0.2672 \\
Gender (\% male) & 53 & 70 & $<0.0001$ \\
Anaemia (\%) & 23 & 10 & $<0.0001$ \\
Thrombocytosis (\%) & 11.5 & 6.7 & 0.0129 \\
Hypercalcemia (\%) & 50 & 58 & 0.0115 \\
Diagnosis to treatment <1 year (\%) & 14 & 13 & 0.7076 \\
Neutrophilia (\%) & 70 & 56 & $<0.0001$ \\
Patients with >1 site of metastasis (\%) & 78 & 81 & 0.3682 \\
Prior nephrectomy (\%) & 9.2 & 5.4 & 0.0315 \\
Brain metastases present (\%) & 4.3 & 9.5 & 0.0254 \\
Sarcomatoid histology (\%) & 7.5 & 15.2 & 0.0002 \\
Non-clear cell histology (\%) & & & \\
\hline
\end{tabular}

Abbreviation: KPS = Karnofsky Performance Status. 


\begin{tabular}{|c|c|c|c|}
\hline & $\begin{array}{l}\text { Non-Asian } \\
\text { population }\end{array}$ & $\begin{array}{c}\text { Asian } \\
\text { population }\end{array}$ & $\boldsymbol{P}$-value \\
\hline $\begin{array}{l}\text { Percentage of dose } \\
\text { modifications/reductions }\end{array}$ & $55 \%$ & $61 \%$ & \begin{tabular}{|l|l|}
0.1197 \\
\end{tabular} \\
\hline $\begin{array}{l}\text { Discontinued treatment due } \\
\text { to toxicity }\end{array}$ & $28 \%$ & $21 \%$ & 0.0197 \\
\hline
\end{tabular}

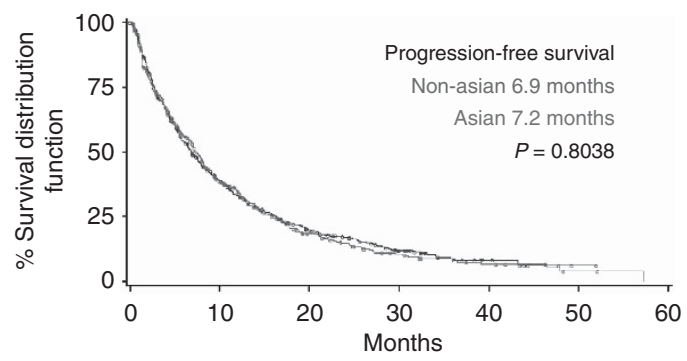

Figure 1. Kaplan-Meier curve of PFS of all patients in Asian vs nonAsian populations. No difference was observed in PFS between Asians (red line) and non-Asians (blue line) $(P=0.8038)$. The full colour version of this figure is available at British Journal of Cancer online.

Table 3. Hazard ratios for death and progression in non-Asian vs Asian populations adjusted for Heng et al prognostic criteria

\begin{tabular}{|l|c|c|c|}
\hline & Hazards ratio & 95\% confidence interval & $\boldsymbol{P}$-value \\
\hline OS & 0.887 & $0.729-1.08$ & 0.2322 \\
\hline PFS & 1.069 & $0.910-1.256$ & 0.4184 \\
\hline
\end{tabular}

Abbreviations: $\mathrm{OS}=$ overall survival; $\mathrm{PFS}=$ progression-free survival.

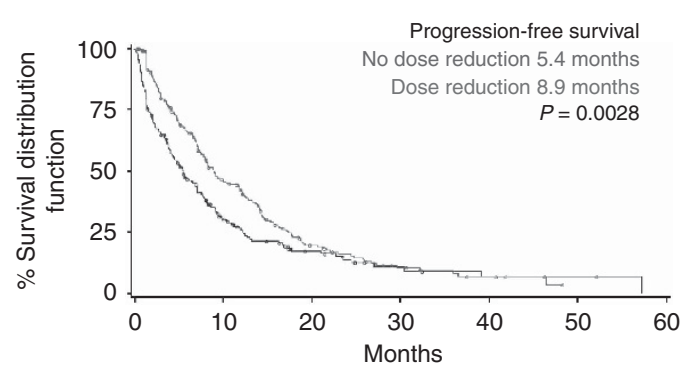

Figure 2. Kaplan-Meier curve of PFS of the Asian population of patients with dose reduction vs those without dose reduction. Patients with dose reduction (red line) had significantly longer PFS compared with patients without dose reduction (blue line) in Asians $(P=0.0028)$. The full colour version of this figure is available at British Journal of Cancer online.

\section{DISCUSSION AND CONCLUSION}

Prior to this analysis, studies demonstrated higher rates of toxicity in Asian patients compared with historical cohorts in clinical trials (Naito et al, 2010). For example, the incidence of hand-foot syndrome (55\% in a Japanese study (Akaza et al, 2007) vs 30\% in the initial landmark phase III study (Escudier et al, 2007)) and hypertension (28\% (Akaza et al, 2007) vs 17\% (Escudier et al, 2007)) with sorafenib in Japanese patients were higher compared with those in clinical trial populations that enrolled few Asians.

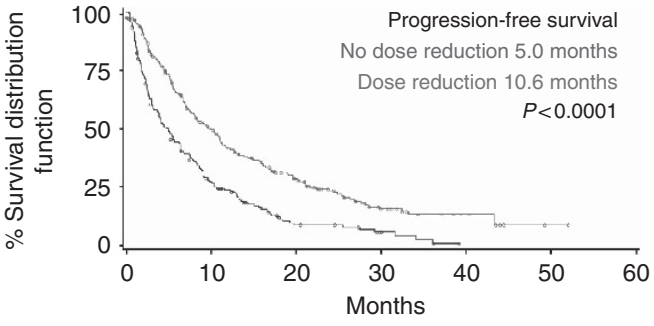

Figure 3. Kaplan-Meier curve of PFS of the non-Asian population of patients with dose reduction vs those without dose reduction. Patients with dose reduction (red line) had significantly longer PFS compared with patients without dose reduction (blue line) in nonAsians $(P<0.0001)$. The full colour version of this figure is available at British Journal of Cancer online.

Table 4. Treatment duration (in months) and OS (in months) in dose reduced vs non-dosed reduced patients of non-Asian and Asian populations

\begin{tabular}{|l|c|c|c|}
\hline & $\begin{array}{c}\text { Dose } \\
\text { reduced }\end{array}$ & $\begin{array}{c}\text { Non-dose } \\
\text { reduced }\end{array}$ & P-value \\
\hline Non-Asians & 10.6 & 5.0 & $<0.0001$ \\
& 16.1 & 0.0016 \\
\hline Treatment duration & 22.6 & 5.4 & 0.0028 \\
OS & \multicolumn{5}{|l}{} \\
\hline Asians & 8.9 & 18.7 & 0.0069 \\
\hline Treatment duration & 28.0 & \\
\hline OS & \multicolumn{5}{|l}{} \\
\hline Abbreviation: OS= overall survival.
\end{tabular}

Similarly, sunitinib demonstrated much more treatment-related hematologic side effects such as thrombocytopenia (Asian $=75 \%$ Kim et al, 2011, non-Asian $=7 \%$ by Motzer et al, 2007) and neutropenia (Asian $=70.5 \%$ by Kim et al, 2011, non-Asian $=6 \%$ Motzer et al, 2007) in Asians compared with non-Asians (Hong et al, 2009; Lee et al, 2009; Naito et al, 2010; Hwang et al, 2010; Yoo et al, 2010; Zhou, 2012). Comparisons across studies (especially between population-based cohorts and clinical trials) may lead to erroneous conclusions as patient population-based cohorts may encounter higher toxicity rates than clinical trial patients as the latter may be a healthier population. This analysis uses populationbased data in Asian and non-Asian centres to allow for a more balanced comparison. One hypothesis that attempts to account for the difference in adverse effect profiles is a lower median body surface area (BSA) in Asian populations (Zhou, 2012). Analysis showed low BSA to be highly predictive of grade 3-4 toxicities (Odds ratio $(\mathrm{OR}) 4.2, P=0.02$ ) in 132 patients on sunitinib for advanced RCC (van der Veldt et al, 2008; Kim et al, 2011). Other studies have identified single nucleotide polymorphisms (SNPs) that are associated with toxicity outcomes, suggesting that these are makers of a linked genetic locus responsible for the difference in these findings in both individual responses and ethnicities (Eechoute et al, 2012; Kim et al, 2013; Scartozzi et al, 2013; Beuselinck et al, 2014). Formal pharmacokinetic analysis of BSA with ethnic variants in SNPs and adverse effect profiles between Asian and non-Asian populations would be helpful.

Although studies outline differences in side-effect profiles between the two populations, no prior study has been conducted to determine if this results in a difference in OS or PFS as the main study outcome. This led us to conduct a multicentre retrospective, population-based analysis of the outcomes in patients who have 
been treated with anti-VEGF therapies in Asian and non-Asian centres. We wondered if differences in toxicity profiles may lead to a greater frequency of dose reductions or discontinuation of treatment, thus affecting response rates between the two populations.

Previous studies involving patients treated with both sunitinib and sorafenib tended towards higher rates of reductions in Asian populations, within the limitations of small sample sizes and differences in study populations (Akaza et al, 2007; Gore et al, 2009; Hong et al, 2009; Lee et al, 2009; Zhang et al, 2009; Hwang et al, 2010; Tomita et al, 2010; Uemura et al, 2010; Yoo et al, 2010; Kim et al, 2011; Tanigawa et al, 2011; Yang et al, 2012). Contrary to previous trends, our results showed the percentage of patients requiring dose modifications/reductions are comparable in the two groups (55\% vs $61 \%$ in non-Asian vs Asians, $P=0.1197)$. This result may reflect increased experience in management of more contemporary patients and physicians' cohesive treatment strategies of side effects regardless of ethnicity. Still, toxicities could be higher in Asian patients, but at least in our study, these did not contribute to a higher rate of dose reductions or treatment discontinuation.

Furthermore, in our study, significantly more patients at nonAsian centres discontinued treatment due to toxicity than did patients in Asian centres ( $28 \%$ vs $21 \%, P=0.0197)$. Interestingly, the PFS and OS of these two populations did not appear to be adversely affected by the difference in the rate of treatment discontinuation. This perhaps points again to variations in SNPs. Non-Asians who discontinued treatment earlier may have received as much overall dosing given individual variations in SNPs to gain equal absolute benefit from treatments regardless of treatment duration, thus not affecting overall PFS and OS (Kim et al, 2013). Further studies are needed to elucidate variations in SNPs and correlation with treatment outcome in our patient population. Overall, this supports individualised treatment of mRCC with close follow-up for side effects and dose management.

Our results are consistent with a subanalysis of Asian vs nonAsian populations in the mRCC expanded-access program (EAP) for sunitinib (Gore et al, 2009; Lee et al, 2009; Zhou, 2012). The EAP study enrolled 4564 patients from 52 countries with mRCC who were ineligible for prior sunitinib clinical trials and received sunitinib on a compassionate-use basis. In the sub-analysis of 325 Asian vs 4046 non-Asian patients, both populations also showed similar OS, 18.9 months in Asian patients (95\% CI: 15.5-23.5), and 18.4 months in non-Asian patients (95\% CI: 17.4-19.2). Despite the lack of adjustments for prognostic factors, the EAP study did agree with this current study on OS and PFS between Asian and non-Asian populations taking sunitinib for mRCC. Although some toxicities in Asians seem to occur with greater frequency and severity, this does not seem to result in a difference in response to treatment between the two populations.

Finally, populations aside, we found that patients who required dose reductions within each sub-population had an increased overall treatment duration, and OS (Table 4). The same results were found in PFS within both populations (Figures 2 and 3). Similarly, in the original landmark phase III trial comparing sunitinib $v s$ IFN, the objective response rate to sunitinib treatment was increased from $37 \%$ after a median treatment of 6 months (95\% CI: 26-36) to $47 \%$ after 11 months in the updated results (95\% CI: 42-52) (Escudier et al, 2007; Motzer et al, 2009). This may suggest an 'area under the curve effect', where higher exposure to the medication for longer durations through individualised dosing strategy, rather than a 'one dose fits all' approach, may be key in conferring a survival advantage (Houk et al, 2010; Ravaud and Bello, 2011). This could also mean that patients that develop toxicity and thus require dose reductions have higher drug exposure than patients who do not require a dose reduction because they are not experiencing toxicity. This has been demonstrated in retrospective studies and is currently being prospectively validated (Bjarnason et al, 2013).
In conclusion, we found that there was no difference in PFS, OS, and dose reductions required between Asian and non-Asian populations. Patients who had dose reductions had longer treatment durations and OS possibly because judicious dose reductions led to better tolerability and longer courses of treatment. Additionally, it may also mean that patients who encounter toxicity requiring dose reductions had higher drug exposures compared with those who did not encounter toxicity requiring dose reductions. Further studies that directly and prospectively test this hypothesis are eagerly anticipated.

\section{ACKNOWLEDGEMENTS}

Authors would like to acknowledge the support they have received from host institutions including cancer centres in Canada (Alberta Health Services Cancer Care, British Columbia Cancer Agency), the United States of America (Dana-Farber Cancer Institute, Beth Israel Deaconess Medical Center), Korea (Asan Medical Center, Yonsei Cancer Center), and Singapore (National Cancer Center).

\section{CONFLICT OF INTEREST}

TKC has received research funding from Pfizer and has an advisory role at Aveo, Pfizer, Novartis, GlaxoSmithKline, Genentech, Bayer, and Onyx. CK has an advisory role at Pfizer, Novartis, and GlaxoSmithKline and has received honoraria and research funding from Pfizer, Novartis, and GlaxoSmithKline. J-LL has received honoraria from Bayer, Pfizer, GSK, Janssen and research funding from Bayer. DYCH has an advisory role at Aveo, Pfizer, Novartis, and Bayer. YW, SAN, M-HT, S-YR, and DFM declare that they have no conflicts of interest.

\section{REFERENCES}

Akaza H, Tsukamoto T, Murai M, Nakajima K, Naito S (2007) Phase II study to investigate the efficacy, safety, and pharmacokinetics of sorafenib in Japanese patients with advanced renal cell carcinoma. Jpn J Clin Oncol 37(10): 755-762.

Beuselinck B, Karadimou A, Lambrechts D, Claes B, Wolter P, Couchy G, Berkers J, van PH, Paridaens R, Schoffski P, Mejean A, Verkarre V, Lerut E, Joly F, Lebret T, Gravis G, Deplanque G, Descazeaud A, Leclercq NR, Molinie V, Patard JJ, Teghom C, Elaidi R, Zucman-Rossi J, Oudard S (2014) VEGFR1 single nucleotide polymorphisms associated with outcome in patients with metastatic renal cell carcinoma treated with sunitinib - a multicentric retrospective analysis. Acta Oncol 53(1): 103-112.

Bjarnason GA, Basappa NS, Knox J, Kollmannsberger C, Reaume N, Zalewski P, Macfarlane RJ, MacKenzie MJ, Hotte SJ, Heng DY, Soulieres D, Miller J (2013) A phase II multicenter study of the efficacy and safety of sunitinib given on an individualized schedule as first-line therapy for metastatic renal cell cancer. J Clin Oncol 31(Suppl): abstr TPS4594.

Eechoute K, van der Veldt AA, Oosting S, Kappers MH, Wessels JA, Gelderblom H, Guchelaar HJ, Reyners AK, van Herpen CM, Haanen JB, Mathijssen RH, Boven E (2012) Polymorphisms in endothelial nitric oxide synthase (eNOS) and vascular endothelial growth factor (VEGF) predict sunitinib-induced hypertension. Clin Pharmacol Ther 92(4): 503-510.

Eisenhauer EA, Therasse P, Bogaerts J, Schwartz LH, Sargent D, Ford R, Dancey J, Arbuck S, Gwyther S, Mooney M, Rubinstein L, Shankar L, Dodd L, Kaplan R, Lacombe D, Verweij J (2009) New response evaluation criteria in solid tumours: revised RECIST guideline (version 1.1). Eur J Cancer 45(2): 228-247.

Escudier B, Eisen T, Stadler WM, Szczylik C, Oudard S, Siebels M, Negrier S, Chevreau C, Solska E, Desai AA, Rolland F, Demkow T, Hutson TE, Gore M, Freeman S, Schwartz B, Shan M, Simantov R, Bukowski RM (2007) Sorafenib in advanced clear-cell renal-cell carcinoma. N Engl J Med 356(2): 125-134. 
Gore ME, Szczylik C, Porta C, Bracarda S, Bjarnason GA, Oudard S, Hariharan S, Lee SH, Haanen J, Castellano D, Vrdoljak E, Schoffski P, Mainwaring P, Nieto A, Yuan J, Bukowski R (2009) Safety and efficacy of sunitinib for metastatic renal-cell carcinoma: an expanded-access trial. Lancet Oncol 10(8): 757-763.

Heng DY, Xie W, Regan MM, Warren MA, Golshayan AR, Sahi C, Eigl BJ, Ruether JD, Cheng T, North S, Venner P, Knox JJ, Chi KN, Kollmannsberger C, McDermott DF, Oh WK, Atkins MB, Bukowski RM, Rini BI, Choueiri TK (2009) Prognostic factors for overall survival in patients with metastatic renal cell carcinoma treated with vascular endothelial growth factor-targeted agents: results from a large, multicenter study. J Clin Oncol 27(34): 5794-5799.

Hong MH, Kim HS, Kim C, Ahn JR, Chon HJ, Shin SJ, Ahn JB, Chung HC, Rha SY (2009) Treatment outcomes of sunitinib treatment in advanced renal cell carcinoma patients: a single cancer center experience in Korea. Cancer Res Treat 41(2): 67-72.

Houk BE, Bello CL, Poland B, Rosen LS, Demetri GD, Motzer RJ (2010) Relationship between exposure to sunitinib and efficacy and tolerability endpoints in patients with cancer: results of a pharmacokinetic/ pharmacodynamic meta-analysis. Cancer Chemother Pharmacol 66(2): 357-371.

Hwang E, Lee HJ, Sul CK, Lim JS (2010) Efficacy and safety of sunitinib on metastatic renal cell carcinoma: a single-institution experience. Korean J Urol 51(7): 450-455.

Kim HR, Park HS, Kwon WS, Lee JH, Tanigawara Y, Lim SM, Kim HS, Shin SJ, Ahn JB, Rha SY (2013) Pharmacogenetic determinants associated with sunitinib-induced toxicity and ethnic difference in Korean metastatic renal cell carcinoma patients. Cancer Chemother Pharmacol 72(4): $825-835$.

Kim HS, Hong MH, Kim K, Shin SJ, Ahn JB, Jeung HC, Chung HC, Koh Y, Lee SH, Bang YJ, Rha SY (2011) Sunitinib for Asian patients with advanced renal cell carcinoma: a comparable efficacy with different toxicity profiles. Oncology 80(5-6): 395-405.

Kollmannsberger C, Soulieres D, Wong R, Scalera A, Gaspo R, Bjarnason G (2007) Sunitinib therapy for metastatic renal cell carcinoma: recommendations for management of side effects. Can Urol Assoc J 1(2 Suppl): S41-S54.

Lee S, Chung HC, Mainwaring P, Ng C, Chang JWC, Kwong P, Li RK, Sriuranpong V, Toh C. K, Lowenthal SP (2009) An Asian subpopulation analysis of the safety and efficacy of sunitinib in metastatic renal cell carcinoma. EJC Suppl 7(2): 428 Ref Type: Abstract.

Motzer RJ, Hutson TE, Tomczak P, Michaelson MD, Bukowski RM, Oudard S, Negrier S, Szczylik C, Pili R, Bjarnason GA, Garcia-del-Muro X, Sosman JA, Solska E, Wilding G, Thompson JA, Kim ST, Chen I, Huang X, Figlin RA (2009) Overall survival and updated results for sunitinib compared with interferon alfa in patients with metastatic renal cell carcinoma. J Clin Oncol 27(22): 3584-3590.

Motzer RJ, Hutson TE, Tomczak P, Michaelson MD, Bukowski RM, Rixe O, Oudard S, Negrier S, Szczylik C, Kim ST, Chen I, Bycott PW, Baum CM, Figlin RA (2007) Sunitinib versus interferon alfa in metastatic renal-cell carcinoma. N Engl J Med 356(2): 115-124.
Naito S, Tomita Y, Rha SY, Uemura H, Oya M, Song HZ, Zhong LH, Wahid MI (2010) Kidney Cancer Working Group report. Jpn J Clin Oncol 40(Suppl 1): i51-i56.

Ravaud A, Bello CL (2011) Exposure-response relationships in patients with metastatic renal cell carcinoma receiving sunitinib: maintaining optimum efficacy in clinical practice. Anticancer Drugs 22(5): 377-383.

Scartozzi M, Bianconi M, Faloppi L, Loretelli C, Bittoni A, Del PM, Giampieri R, Maccaroni E, Nicoletti S, Burattini L, Minardi D, Muzzonigro G, Montironi R, Cascinu S (2013) VEGF and VEGFR polymorphisms affect clinical outcome in advanced renal cell carcinoma patients receiving first-line sunitinib. Br J Cancer 108(5): 1126-1132.

Tanigawa G, Kawashima A, Yamaguchi S, Nishimura K, Miyoshi S, Kajikawa J, Meguro N, Yosioka T, Oka T, Hara T, Takayama H, Nonomura N (2011) Clinical outcome and prognostic factors of sorafenib in Japanese patients with advanced renal cell carcinoma in general clinical practice. Jpn J Clin Oncol 41(11): 1265-1270.

Telli ML, Witteles RM, Fisher GA, Srinivas S (2008) Cardiotoxicity associated with the cancer therapeutic agent sunitinib malate. Ann Oncol 19(9): $1613-1618$.

Tomita Y, Shinohara N, Yuasa T, Fujimoto H, Niwakawa M, Mugiya S, Miki T, Uemura H, Nonomura N, Takahashi M, Hasegawa Y, Agata N, Houk B, Naito S, Akaza H (2010) Overall survival and updated results from a phase II study of sunitinib in Japanese patients with metastatic renal cell carcinoma. Jpn J Clin Oncol 40(12): 1166-1172.

Uemura H, Shinohara N, Yuasa T, Tomita Y, Fujimoto H, Niwakawa M, Mugiya S, Miki T, Nonomura N, Takahashi M, Hasegawa Y, Agata N, Houk B, Naito S, Akaza H (2010) A phase II study of sunitinib in Japanese patients with metastatic renal cell carcinoma: insights into the treatment, efficacy and safety. Jpn J Clin Oncol 40(3): 194-202.

van der Veldt AA, Boven E, Helgason HH, van WM, Berkhof J, de GG, Mallo H, Tillier CN, van den Eertwegh AJ, Haanen JB (2008) Predictive factors for severe toxicity of sunitinib in unselected patients with advanced renal cell cancer. Br J Cancer 99(2): 259-265.

Yang L, Shi L, Fu Q, Xiong H, Zhang M, Yu S (2012) Efficacy and safety of sorafenib in advanced renal cell carcinoma patients: results from a longterm study. Oncol Lett 3(4): 935-939.

Yoo C, Kim JE, Lee JL, Ahn JH, Lee DH, Lee JS, Na S, Kim CS, Hong JH, Hong B, Song C, Ahn H (2010) The efficacy and safety of sunitinib in korean patients with advanced renal cell carcinoma: high incidence of toxicity leads to frequent dose reduction. Jpn J Clin Oncol 40(10): 980-985.

Zhang H, Dong B, Lu JJ, Yao X, Zhang S, Dai B, Shen Y, Zhu Y, Ye D, Huang Y (2009) Efficacy of sorafenib on metastatic renal cell carcinoma in Asian patients: results from a multicenter study. BMC Cancer 9: 249.

Zhou A (2012) Management of sunitinib adverse events in renal cell carcinoma patients: the Asian experience. Asia Pac J Clin Oncol 8(2): 132-144.

This work is published under the standard license to publish agreement. After 12 months the work will become freely available and the license terms will switch to a Creative Commons AttributionNonCommercial-Share Alike 3.0 Unported License. 